Vol.14,\#3, Junio 2008

http://revista-redes.rediris.es

\title{
Organizaciones, redes, innovación y competitividad territorial: análisis del caso Bahía Blanca
}

\author{
José Ignacio Diez - Univ. Nac. del Sur - CONICET ${ }^{1}$
}

\section{Resumen}

En los últimos años, distintas corrientes de pensamiento económico están revalorizando el papel que juegan los ambientes o entornos locales en la acumulación de capital.

Este artículo analiza el comportamiento de las organizaciones de apoyo a la producción del partido de Bahía Blanca con el propósito de entender en qué medida el sistema institucional es capaz de promover el desarrollo económico de la localidad. A tal efecto, se combinan estadísticas descriptivas tradicionales con análisis de redes sociales para evaluar la performance del tejido organizacional.

Los principales resultados obtenidos arrojan que el medio institucional es poco dinámico, medido tanto en términos de comunicaciones como en cantidad de proyectos conjuntos.

Palabras clave: Atmósfera institucional, redes, competitividad, desarrollo económico local.

\begin{abstract}
In the last years, different economic schools are reconsidering the role that local environment is playing in capital accumulation.

This article analyzes the behaviour of institutional atmosphere in Bahia Blanca in order to understand if local organizations are capable of promoting economic development. To achieve that goal, the paper combines traditional statistics methods with social network analysis.
\end{abstract}

The main results show that the institutional atmosphere is not playing an important role in promoting economic growth, measured in terms of communications and joint projects.

Key words: Institutional atmosphere; networks, competitiveness; local economic development.

\section{I ntroducción}

Una parte sustancial de las investigaciones dedicadas a interpretar las transformaciones socioeconómicas y territoriales asociadas a la nueva fase de desarrollo capitalista incorpora como referentes centrales a los procesos de competencia e innovación y al espacio de interacción conformado por flujos y redes.

\footnotetext{
${ }^{1}$ Enviar correspondencia a: José Ignacio Diez jdiez@uns.edu.ar
} 
REDES- Revista hispana para el análisis de redes sociales

Vol.14,\#3, Junio 2008

http: // revista-redes.rediris.es

Se consolida así la idea de que los esfuerzos competitivos e innovadores, que propician la generación e incorporación de conocimientos para dar respuesta a los retos y problemas de las sociedades contemporáneas, resultan ser factores claves que permiten, no sólo a las empresas, sino también a los distintos ámbitos territoriales, insertarse mejor en el concierto de la economía globalizada (Aydalot, 1986; Maillat, 1995; Colletis y Pecqueur; 1995).

A diferencia de períodos anteriores en los cuales la atención de los intelectuales y académicos se centraba en el estudio de la capacidades competitivas de las empresas, hoy cobra relevancia el papel asumido por el territorio en la generación y apropiación del conocimiento y por lo tanto, en la acumulación de capital.

En este sentido, el espacio deja de ser un mero soporte o escenario en el cual discurren los acontecimientos para convertirse en un actor más del desarrollo.

El territorio, encarnado en sus organizaciones de apoyo a la producción, se convierte en un factor capaz de desencadenar ventajas competitivas dinámicas, las cuales se generan a través del uso y explotación de los recursos materiales e inmateriales presentes en cada una de las localidades.

La óptima utilización de tales recursos está ligada a su vez, a la acción colectiva y a la formación de redes, capaces de explotar las sinergias factibles entre las diferentes entidades.

Respecto a esta cuestión, Vázquez Barquero (2001) sostiene que los espacios ganadores de la globalización son aquellos que tienen un sistema institucional evolucionado y complejo, donde existen redes densas de relaciones entre instituciones de formación e investigación, asociaciones de empresarios y gobiernos locales que facilitan y promueven la innovación, la acumulación de capital y el crecimiento sostenido.

Según el autor, las barreras al crecimiento económico aparecen frecuentemente como consecuencia de las carencias y mal funcionamiento de dicha red, que limitan tanto inversiones como procesos de aprendizaje colectivo.

Partiendo de estos conceptos, el presente trabajo tiene como objetivo analizar el comportamiento de las organizaciones de apoyo a la producción en el partido de Bahía Blanca y el entramado de relaciones en que estas interactúan con el propósito de entender, en qué medida el sistema institucional puede favorecer o no el desarrollo económico de la localidad. 
REDES- Revista hispana para el análisis de redes sociales

Vol.14,\#3, Junio 2008

http: // revista-redes.rediris.es

En primer lugar, se presenta el marco teórico de la investigación, haciendo hincapié en el concepto de medio, atmósfera o entorno y en la noción de red.

En segundo lugar, se presenta la metodología utilizada en el trabajo de campo.

En tercer término, se realiza una caracterización de las organizaciones entrevistadas de acuerdo a una serie de requisitos considerados esenciales para administrar eficientemente los recursos existentes en una red.

En cuarto lugar, se analiza la comunicación en el sistema considerado utilizando la técnica de social network analysis.

En quinto término, se consideran los proyectos conjuntos realizados por las distintas entidades con el objetivo de promover el desarrollo económico de la localidad.

Por último, se presentan resultados sobre hegemonías o liderazgos en la trama analizada con el propósito de entender la capacidad del sistema para promover esfuerzos concertados.

A modo de conclusión, se realiza un análisis pormenorizado de los indicadores presentados, considerando tanto los resultados en términos sistémicos como la situación individual de los principales actores involucrados.

\section{Atmósfera institucional y redes}

En los últimos años, los ámbitos locales comienzan a ser revalorizados como "ambientes o entornos" socioeconómicos e institucionales dinámicos que favorecen la cooperación empresarial (redes asociativas y alianzas estratégicas), la articulación público-privada y el desarrollo de capacidades innovadoras en el aparato productivo.

En el contexto de la globalización, las empresas ya no compiten en forma aislada o descontextualizada, sino que lo hacen el marco de interdependencias económicas e institucionales.

Los nuevos paradigmas tecno-organizacionales, la posibilidad de combinar economías de escala y alcance, la mundialización de los mercados, la volatilidad de la demanda, el agotamiento del ciclo de vida del producto y los cambios producidos en la tecnología de la información y la comunicación, están aumentando la incertidumbre estratégica que sufren las empresas. 
REDES- Revista hispana para el análisis de redes sociales

Vol.14,\#3, Junio 2008

http: //revista-redes.rediris.es

Para poder sobrevivir en mercados cada vez más complejos, las firmas necesitan mejorar productos, procesos y desarrollar cambios organizacionales que les permitan generar nuevas capacidades competitivas.

Habitualmente, estas capacidades no pueden ser desarrolladas en forma individual por lo resulta necesario establecer relaciones con el medio o entorno, el cual se constituye en el instrumento capaz de mejorar la productividad de la empresa, ya que actúa potenciando los procesos de aprendizaje e innovación, realizando informalmente funciones de investigación, transmisión, selección, decodificación, transformación y control de la información, que permiten la emergencia de ventajas cooperativas.

De esta forma el medio o entorno se constituye en un nuevo actor del desarrollo territorial ya que a través de su accionar promueve fertilidad y atractividad, entendiendo por fertilidad la promoción y consolidación de empresas de capital local y por atractividad la capacidad para atraer inversiones foráneas. (De Mattos et al, 2004).

El medio o entorno está constituido por organizaciones de diverso tipo: instituciones científicas y tecnológicas, gobierno local, entidades de comercialización, gremiales empresarias, entes descentralizados, etc. y puede tener distinto tamaño en función de la escala (local, regional) que se esté considerando.

La atmósfera institucional tiene la capacidad de poner en valor recursos materiales (infraestructuras físicas y tecnológicas) e inmateriales (saber hacer, conocimientos tácitos y codificados) que se encuentran subutilizados en el territorio.

Mediante el espacio de las redes, las diversas organizaciones se comunican y comparten recursos y capacidades, construyendo espacios de trabajo común que permiten el desarrollo de proyectos e innovaciones.

A través de estas iniciativas el espacio local logra captar rentas extraordinarias que se traducen en beneficios económicos para toda la sociedad.

En este sentido, los beneficios del trabajo en red son múltiples, ya que la cooperación permite enfrentar problemas complejos que serían imposibles de abordar por un solo actor. 
REDES- Revista hispana para el análisis de redes sociales

Vol.14,\#3, Junio 2008

http: // revista-redes.rediris.es

De acuerdo a Harrigan (1992), las ventajas del trabajo cooperativo son las siguientes:

a) Beneficios internos: riesgos compartidos, mejor información y prácticas, evita duplicación de esfuerzos. Generación de externalidades.

b) Beneficios competitivos: Influencia sobre la evolución del sector y/o la economía que se trate. Mejor posicionamiento y diferenciación.

c) Beneficios Estratégicos: Sinergias, transferencia de capacidades y de tecnología, posibilidades de diversificación.

Por su parte, para que las redes funcionen adecuadamente, debe existir una conexión confiable entre los agentes (tanto en términos de infraestructura tecnológica básica como en lo que respecta a lazos de cordialidad y confidencia entre las personas e instituciones). Respecto a esta cuestión, puede decirse que la construcción de entornos dinámicos y redes esta íntimamente vinculada a la noción de Capital Social, entendido este como actitudes de confianza que se dan en combinación con conductas de reciprocidad y colaboración (Durston, 2002).

A su vez, la presencia de una red activa supone la existencia de contenidos comunicables entre las partes involucradas, en el sentido de disponibilidad de datos e información y mecanismos de interpretación.

Así mismo, un espacio reticular con funcionamiento adecuado necesita la presencia de miembros que funcionan con capacidad efectiva, institucional e individual para desempeñar tareas específicas y esenciales (Choucri, 1998).

Esta cuestión no resulta menor, ya que pareciera existir cierto umbral mínimo necesario de capacidades organizacionales e individuales para lograr explotar adecuadamente los recursos existentes en una red.

\section{Metodología}

Para cumplir con los objetivos planteados en la investigación, se realizaron distintas actividades las cuales se detallan a continuación:

- Determinación del universo de estudio.

- Confección del cuestionario base para la investigación.

- Sensibilización del grupo objetivo. 
REDES- Revista hispana para el análisis de redes sociales

Vol.14,\#3, Junio 2008

http: // revista-redes.rediris.es

- Formulación de entrevistas.

- Procesamiento y análisis de la información relevada.

Para la determinación del universo de estudio se solicitó la colaboración de informantes clave, personas con un profundo conocimiento de Bahía Blanca y sus organizaciones.

Se relevaron un total de 33 instituciones de apoyo a la producción, las cuales se clasificaron en 6 categorías: Entidades Gremiales, Gobierno Local y Entes Públicos no Gubernamentales, Sistema Científico-Tecnológico, Banca de Fomento, entidades de Comercialización y otras organizaciones (ver Anexo1).

Para la confección del formulario base de la investigación, se utilizó como antecedente trabajos previos en la materia ${ }^{2}$.

La actividad de sensibilización consistió en reuniones de presentación de los alcances del trabajo con los representantes de las diferentes instituciones.

La obtención de los datos primarios de la encuesta se realizó entre los meses de octubre de 2005 y febrero de 2006.

\section{Caracterización de las organizaciones del entramado}

El paso de un modelo de organización del territorio de carácter desarticulado y jerárquico hacia un nuevo modelo en forma de red supone contar con instituciones capaces de asumir el desafío que implica desarrollar capacidades gerenciales que permitan establecer relaciones de carácter cooperativo entre las diferentes asociaciones.

Según Boisier (1997) existen cuatro características básicas que definen a una institución capaz de trabajar en forma reticular: la velocidad para reaccionar frente a cambios rápidos en el entorno, la flexibilidad que posibilita dar respuestas diversas (de grande o pequeña escala, coyunturales o estructurales, etc.) de acuerdo a las demandas del exterior, la virtualidad como condición para hacer arreglos de cooperación en el espacio cibernético y la inteligencia, definida como la capacidad para aprender de la propia experiencia que surge en la relación con el otro.

\footnotetext{
2 Ver Dominguez Ares (1997); Costamagna (2000); D’Annunzio (2000); Ferraro y Costamagna (2002); Erbiti (2004).
} 
REDES- Revista hispana para el análisis de redes sociales

Vol.14,\#3, Junio 2008

http: // revista-redes.rediris.es

En relación a este último punto, Morgan (1986) sostiene que las organizaciones son sistemas de procesamiento de información, que atrapan y filtran los conocimientos que circulan en el entorno, los procesan en términos de lo que han aprendido, los interpretan, los cambian y actúan sobre ellos.

Desde esta perspectiva, para poder pasar de un modelo de corte individualista a uno de tipo sistémico y relacional, resulta necesario contar con una dotación recursos organizacionales que permitan administrar la complejidad.

En este sentido, el cambio de paradigma obliga a cada institución a contar con una estructura organizacional mínima que le permita cumplir al menos tres objetivos:

En primer lugar, manejar grandes flujos de información que entran y salen de la organización y que deben a su vez, ser procesados y asimilados por la misma.

En segundo lugar, ser capaces de generar conocimientos a medida de los requerimientos y necesidades del resto de las organizaciones que integran el entramado.

En tercer lugar, supone contar con recursos técnicos que permitan mantener comunicaciones fluidas en tiempo real, facilitando el intercambio de diferentes conceptos y experiencias.

Para poder testear la presencia o ausencia de estos atributos en cada una de las instituciones, se desarrollaron una serie de preguntas que apuntaban a conocer:

- Disponibilidad y calificación del personal en cada organización, considerando exclusivamente aquel vinculado a la actividad principal o a aquella área de la organización que resultase de interés para el estudio.

- Presencia o ausencia de capacitaciones.

- Disponibilidad de equipos, entendiéndose como aquellos que permiten a la organización desempeñar adecuadamente sus actividades.

- Disponibilidad de recursos técnicos asociados a la comunicación.

Los resultados correspondientes a la disponibilidad de personal se presentan en la Tabla 1. 
REDES- Revista hispana para el análisis de redes sociales

Vol.14,\#3, Junio 2008

http://revista-redes.rediris.es

\begin{tabular}{|l|c|c|}
\hline & Número de Organizaciones & $\%$ \\
\hline ADECUADA & 21 & $64 \%$ \\
\hline NO ADECUADA & 12 & $36 \%$ \\
\hline TOTAL & 33 & $100 \%$ \\
\hline
\end{tabular}

Fuente: elaboración propia a partir de los resultados del trabajo de campo.

Tabla 1

El $64 \%$ de las organizaciones entrevistadas consideró disponer de personal adecuado para desarrollar sus actividades, mientras que sólo el 36\% manifestó no estar conforme con la cantidad de personal disponible.

Dos de las organizaciones (FUNDACIÓN EXPORTAR e IDEB) plantearon no disponer de personal propio en Bahía Blanca.

La Tabla 2 muestra la calificación del personal en las organizaciones analizadas.

\begin{tabular}{|c|c|c|}
\hline & $\begin{array}{c}\text { Número de } \\
\text { Organizaciones }\end{array}$ & $\%$ \\
\hline ALTA $^{3}$ & 32 & $97 \%$ \\
\hline MEDIA & 18 & $54 \%$ \\
\hline BAJA & 1 & $3 \%$ \\
\hline
\end{tabular}

Fuente: elaboración propia a partir de los resultados del trabajo de campo.

Tabla 2

De acuerdo a los datos, $97 \%$ de las organizaciones entrevistadas dispone de personal de calificación alta.

En este sentido, cabe aclarar que las organizaciones del sistema científico tecnológico (UNS, UTN, INIBIBB, CRIBABB, CERZOS, PLAPIQUI, IADO, LANAIS N15) manifestaron tener personal técnico y de investigación con formación aún superior (magister y doctorado).

Tanto en el ámbito de la UNS como de la UTN, también se registro personal administrativo del área de extensión universitaria tomando cursos de magister.

Otras, como ser el caso de las unidades de vinculación tecnológica (FUNS, FUNDASUR y FUNDATEC) manifestaron tener directores con formación superior.

3 Alta: Universitario/Terciario Completo o incompleto; Media: Secundario/Polimodal completo o incompleto. Baja: se entiende nivel primario/EGB1-2 completo o incompleto. 
REDES- Revista hispana para el análisis de redes sociales

Vol.14,\#3, Junio 2008

http://revista-redes.rediris.es

Además, un $54 \%$ de las organizaciones dispone de personal de calificación MEDIA y sólo 1 organización (SOCIEDAD RURAL) manifestó tener personal de calificación baja.

La información sobre actividades de capacitación se presenta a continuación.

\begin{tabular}{|c|c|c|}
\hline & $\begin{array}{c}\text { Número de } \\
\text { Organizaciones }\end{array}$ & $\%$ \\
\hline RECIBE & 31 & $94 \%$ \\
\hline NO RECIBE & 2 & $6 \%$ \\
\hline TOTAL & 33 & $100 \%$ \\
\hline
\end{tabular}

Fuente: elaboración propia a partir de los resultados del trabajo de campo.

Tabla 3

El $94 \%$ de las organizaciones entrevistadas manifestó que el personal recibía capacitaciones. Cuando se indagó a los entrevistados sobre las características de las mismas, sus respuestas carecieron de especificidad.

En el caso de las entidades gremiales empresarias los entrevistados sostuvieron que se insta a los empleados a participar de la oferta de cursos que la institución brinda a sus asociados.

En el caso de las Universidades Nacionales (UNS, UTN) y los institutos científicos del CONICET (INIBIBB, PLAPIQUI, CRIBABB, IADO, CERZOS) se planteo que la propia dinámica del sistema científico obliga a la capacitación continua del personal abocado a la investigación, ya que a través de ella el mismo puede lograr recategorizaciones.

En este sentido, la capacitación que se recibe es diversa de acuerdo al área de investigación que se trate.

En cuanto al personal técnico y administrativo de estas organizaciones, se sostuvo que al primero se lo capacita en situaciones eventuales como ser la compra de un nuevo instrumental y el segundo recibe un adiestramiento antes de iniciarse en la organización sobre el manejo de normativa general. Este tipo de capacitación inicial también es habitual en el caso de dos de las unidades de vinculación tecnológica (FUNDASUR, FUNDATEC).

Otras instituciones (TRADEPOINT, F MERCADO, CREEBBA, CGPBB) manifestaron que sólo capacitan a su personal en caso de registrarse necesidades puntales. En el caso del TRADEPOINT Bahía Blanca-Coronel Rosales se capacitó al personal en el manejo de un software para la detección de oportunidades comerciales, mientras que el CGPBB ha enviado personal técnico y directores a recibir capacitación sobre administración portuaria al extranjero. 
REDES- Revista hispana para el análisis de redes sociales

Vol.14,\#3, Junio 2008

http: // revista-redes.rediris.es

Un caso excepcional es el de la banca de fomento (NACION, PCIA Y CREDICOOP). En estas organizaciones el personal entrevistado manifestó la existencia de un sistema de capacitación programada en diversas áreas temáticas, como ser informática y atención al cliente.

Sólo dos organizaciones (MBB y FUNS) manifestaron no promover capacitaciones.

La Tabla 4 muestra la información sobre el equipamiento disponible.

\begin{tabular}{|c|c|c|}
\hline & $\begin{array}{c}\text { Número de } \\
\text { Organizaciones }\end{array}$ & $\%$ \\
\hline ADECUADO & 31 & $94 \%$ \\
\hline INADECUADO & 2 & $6 \%$ \\
\hline TOTAL & 33 & $100 \%$ \\
\hline
\end{tabular}

Fuente: elaboración propia a partir de los resultados del trabajo de campo.

Tabla 4

Del total de entrevistados, un $94 \%$ considero el equipamiento como adecuado, mientras que sólo dos organizaciones (MBB e INTA) consideraron el equipamiento inadecuado para el desenvolvimiento normal de sus actividades.

En el caso del INTA las falencias de equipamiento se compensan a través de un convenio con el Departamento de Agronomía de la UNS que le permite disponer de una parte del instrumental necesario para efectuar sus funciones.

Por otro lado, el representante de la MBB consideró inconveniente la cantidad y calidad de computadoras disponibles en la Dirección de Producción.

Por último, la Tabla 5 muestra los recursos técnicos asociados a la comunicación disponible entre las organizaciones.

\begin{tabular}{|c|c|c|}
\hline & $\begin{array}{c}\text { Número de } \\
\text { organizaciones }\end{array}$ & $\%$ \\
\hline TELEFÓNO & 33 & $100 \%$ \\
\hline FAX & 33 & $100 \%$ \\
\hline INTERNET/MAIL & 33 & $100 \%$ \\
\hline SITIO WEB & 28 & $85 \%$ \\
\hline
\end{tabular}

Fuente: elaboración propia a partir de los resultados del trabajo de campo.

Tabla 5

El $100 \%$ de los entrevistados manifestó disponer de teléfono, fax y servicio de internet/mail, mientras que un $85 \%$ sostuvo disponer de un sitio web.

Las organizaciones que manifestaron carecer de él fueron, AIQBB, IDEB y AGANYAGRI, F MERCADO. 
REDES- Revista hispana para el análisis de redes sociales

Vol.14,\#3, Junio 2008

http: // revista-redes.rediris.es

\section{La comunicación entre las organizaciones de apoyo a la producción en Bahía Blanca}

Escarpit (1976) plantea que las comunicaciones (el intercambio de información y la transmisión de significado) son la esencia misma de un sistema u organización social.

Por definición, el proceso de comunicación es un proceso de relaciones, donde puede o no existir interacción o reciprocidad.

Maisonneuve (1968) sostiene que la interacción tiene lugar cuando una unidad de acción producida por un sujeto A actúa como estímulo de una unidad de respuesta en otro sujeto, B, y viceversa.

En este sentido, el modelo de referencia para entender el proceso de comunicación es sin duda el que la presenta como transferencia de un mensaje bajo la forma de señal, desde una fuente de información, por medio de un emisor y un receptor y donde dicha transmisión puede ser afectada por la presencia de fenómenos parasitarios llamados "ruidos" (Shannon y Weaver, 1949).

La Ilustración 1 muestra el esquema básico de la comunicación.

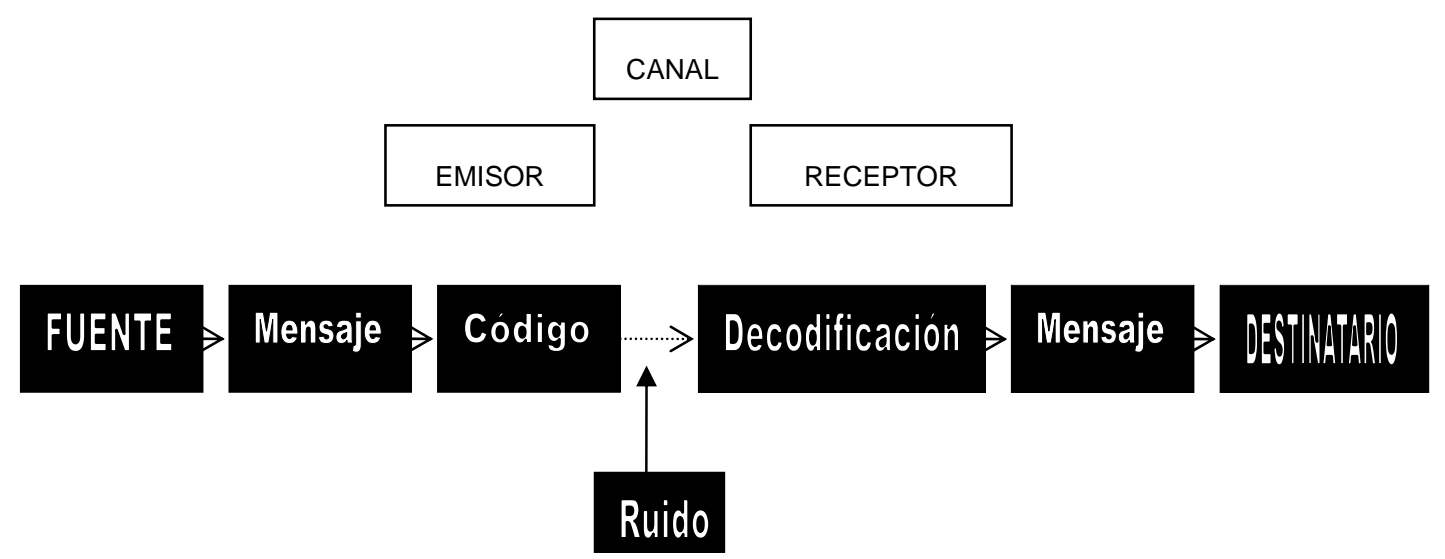

Fuente: EDMOND, Marc, PICARD,Dominique (1992) La interacción social, Barcelona, Ed. Paidos,

I lustración 1. Esquema básico de comunicación. 
REDES- Revista hispana para el análisis de redes sociales

Vol.14,\#3, Junio 2008

http://revista-redes.rediris.es

Para incorporar la idea de interacción, los modelos de tipo técnico se apoyan en la noción de feedback, traducida al castellano como "retracción" la cual designa la reacción del receptor al mensaje emitido y su retorno hacia el emisor.

Esta idea conduce a considerar que la fuente y el destinatario son de hecho "emisores-receptores" que ejercen funciones diferenciadas en un proceso circular y no lineal, como en el esquema anterior.

Apoyándose en estos modelos básicos, se analiza el proceso de comunicación existente en el entramado de apoyo a la producción en Bahía Blanca, considerando la comunicación efectiva ${ }^{4}$ entre las organizaciones.

Utilizando los programas UCINET ${ }^{5}$ y NETDRAW ${ }^{6}$ se puede visualizar (Ilustración 2) el esquema de relaciones vigente entre las entidades analizadas.

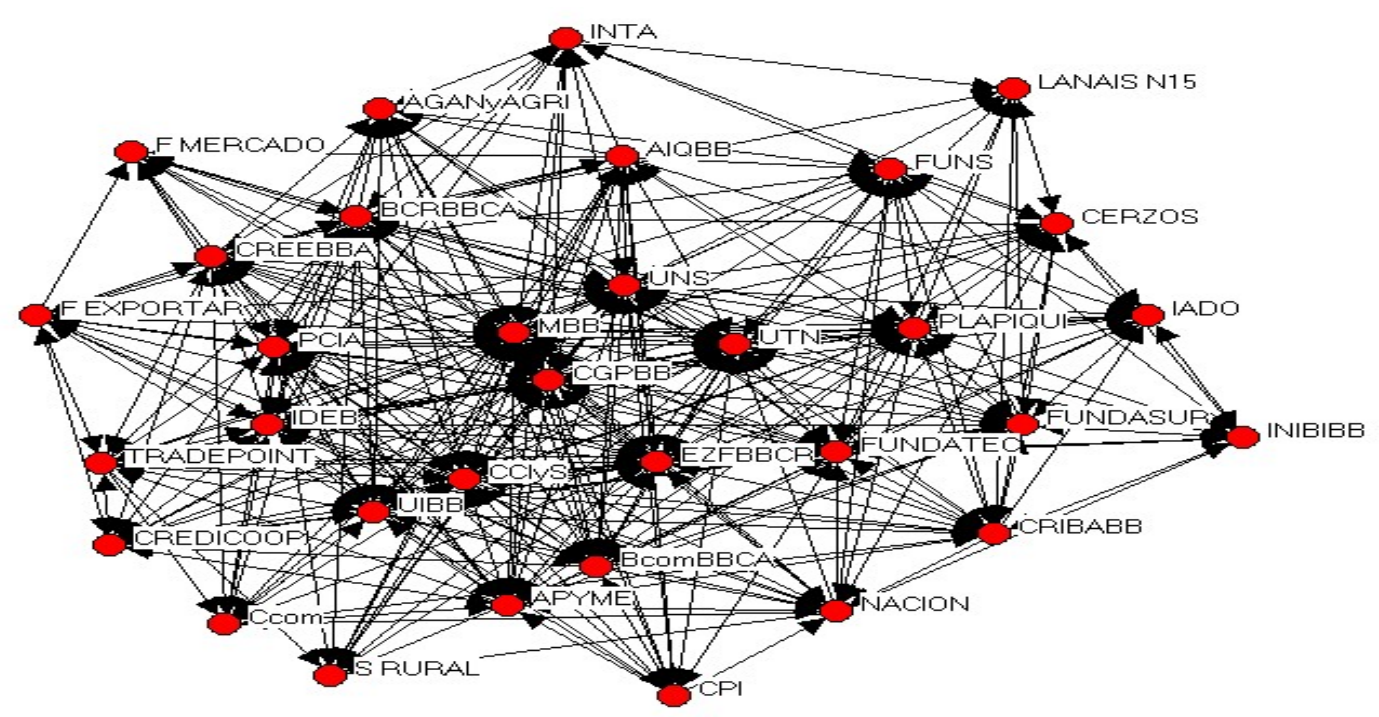

I lustración 2. Relaciones entre las entidades.

\footnotetext{
${ }^{4}$ Surge de cruzar los datos correspondientes a quién envía y de quién recibe información cada una de las organizaciones del entramado. La matriz construida para registrar los datos es cuadrada, idéntica y normal, ya que permite tanto flujos unidireccionales como bidireccionales. La información registrada en la matriz no contempla la frecuencia de los contactos.

${ }^{5}$ BORGATTI, S.P.,EVERETT, M. G. Y FREEMAN, L. C. (2002). Ucinet for Windows: Software for Social Network Analysis. Harvard, MA: Analytic Technologies.

${ }^{6}$ BORGATTI, S. P. (2002). Netdraw: Graph Visualization Software. Harvard: Analytic Technologies.
} 
REDES- Revista hispana para el análisis de redes sociales

Vol.14,\#3, Junio 2008

http: // revista-redes.rediris.es

De la mera observación del grafo se puede intuir la presencia de al menos 6 (seis) actores centrales (MBB, CGPBB, UNS, UTN, EZFBBCR, CClyS) en el sistema considerado, de los cuales tres de ellos se encuentran dentro de la categoría Entes Públicos, uno en la categoría gremiales empresarias y dos en la categoría Sistema Científico Tecnológico. Con relación a esta última categoría, podemos afirmar que la mayoría de los agentes juega un rol periférico en la red, con excepción de PLAPIQUI y FUNDATEC, que se encuentran cercanos al núcleo de relaciones.

Por otro lado, dentro de la categoría Banca de Fomento, el actor con mayor cantidad de relaciones es el Banco Provincia de Buenos Aires ( $\mathrm{PCI} A$ ) mientras que en la categoría otros actores, el IDEB aparece como el agente con mayor cantidad de contactos.

Por último, entre las entidades vinculadas a la comercialización, la de mayor densidad de vínculos parece ser la BCRBBCA, que a su vez, es la organización que más contactos presenta de todas las entidades relacionadas directamente con el sector agropecuario (AGANyAGRI, SOCIEDAD RURAL, CERZOS, INTA).

A continuación, se avanza en el estudio de las comunicaciones interinstitucionales a través de distintos indicadores (densidad de la red, grado de centralidad, centralidad de cercanía y grado de intermediación).

\subsection{Densidad de la red}

El tamaño de una red es un factor crítico para cualquier estructura de relaciones sociales ya que los actores disponen de recursos y capacidades limitadas para construir y mantener lazos.

La medida de densidad de una red muestra hasta qué punto el entramado alcanza su potencial máximo o situación de saturación, considerando la relación que existe entre cantidad de lazos presentes frente a la cantidad de lazos posibles.

Para nuestro caso de estudio, el total de lazos presentes entre las organizaciones es de 510 vínculos, sobre un total de 1056 posibles, lo que arroja una densidad del $48 \%$. Esta situación da cuenta de una importante cantidad de orificios estructurales en el entramado considerado. 
REDES- Revista hispana para el análisis de redes sociales

Vol.14,\#3, Junio 2008

http: // revista-redes.rediris.es

\subsection{Grado de Centralidad}

El grado de centralidad muestra el número de actores a los cuales una organización está directamente unido.

De acuerdo a este enfoque, las entidades que tienen mayor cantidad de vínculos disponen de una posición ventajosa en la red, ya que pueden acceder a más conocimientos e información, satisfaciendo de esta forma un mayor número de necesidades.

El Tabla 6 muestra la información sobre centralidad correspondiente a la Ilustración 2.

\begin{tabular}{|ll|c|c|c|c|}
\hline & & OutDegree & I nDegree & NrmOutDeg & NrmI nDeg \\
\hline 7 & MBB & 30.000 & 27.000 & 93.750 & 84.375 \\
\hline 8 & UNS & 29.000 & 26.000 & 90.625 & 81.250 \\
\hline 17 & CGPBB & 28.000 & 24.000 & 87.500 & 75.000 \\
\hline 1 & CClyS & 25.000 & 19.000 & 78.125 & 59.375 \\
\hline 11 & UTN & 25.000 & 24.000 & 78.125 & 75.000 \\
\hline 3 & UIBB & 21.000 & 21.000 & 65.625 & 65.625 \\
\hline 19 & EZFBBCR & 19.000 & 25.000 & 59.375 & 78.125 \\
\hline
\end{tabular}

Tabla 6

De acuerdo a los datos, la organización que envía más información (mayor grado de salida) es la MBB con un total de 30 vínculos; en orden de importancia las organizaciones que la siguen son la UNS, con un total de 29 lazos, seguido del CGPBB con 28 y la CClyS junto a la UTN con 25 contactos.

En este sentido, estos cinco actores pueden ser considerados como los más influyentes en el esquema de relaciones.

En cuanto a los grados de entrada (organización que más recibe información), los actores más importantes son nuevamente la MBB con un total de 27 lazos seguida de la UNS con 26, el EZFBBCR con 25 y el CGPBB y la UTN con 24, respectivamente.

Este último grupo de actores puede considerarse como prestigioso o prominente dentro de la red.

El intento por parte del resto de los agentes de compartir conocimientos con ellos puede ser interpretado como un acto de deferencia o reconocimiento de sus posiciones en la trama de relaciones. 
REDES- Revista hispana para el análisis de redes sociales

Vol.14,\#3, Junio 2008

http: // revista-redes.rediris.es

A continuación se muestra información estadística sobre el nivel meso y macro de la red.

\begin{tabular}{|c|c|c|c|c|}
\hline & OutDegree & InDegree & NrmOutDeg & NrmI nDeg \\
\hline Mean & 15.424 & 15.424 & 48.201 & 48.201 \\
\hline 2 Std Dev & 7.015 & 5.668 & 21.923 & 17.712 \\
\hline Sum & 509.000 & 509.000 & 1.590 .625 & 1.590 .625 \\
\hline 4 Variance & 49.214 & 32.123 & 480.605 & 313.702 \\
\hline SSQ & 9.475 .000 & 8.911 .000 & 92.529 .297 & 87.021 .484 \\
\hline 6 MCSSQ & 1.624 .061 & 1.060 .061 & 15.859 .967 & 10.352 .154 \\
\hline 7 Euc Norm & 97.340 & 94.398 & 304.186 & 294.994 \\
\hline 8 Minimum & 2.000 & 7.000 & 6.250 & 21.875 \\
\hline 9 Maximum & 30.000 & 27.000 & 93.750 & 84.375 \\
\hline
\end{tabular}

Network Centralization (Outdegree) $=46.973 \%$

Network Centralization (Indegree) $=37.305 \%$

Tabla 7

De acuerdo a la información del cuadro, puede observarse que en promedio los actores tienen un total de 15 lazos de entrada y salida respectivamente.

Si bien este valor puede considerarse elevado, el desvío estándar (tanto de salida como de entrada) también es alto, lo que indica posiciones heterogéneas en la red.

Esta situación puede corroborarse a partir de la información sobre lazos mínimos y máximos de entrada y salida, que muestra una fluctuación importante.

Por último, las medidas de centralización de grafo de Freeman muestran valores significativos ( $46 \%$ y $37 \%$ respectivamente), lo que indica la presencia de un número pequeño de actores que concentra las comunicaciones entre las organizaciones.

\subsection{Centralidad de Cercanía}

La medida grado de centralidad muestra sólo los vínculos inmediatos o lazos directos que tiene cada actor y no considera los contactos que una organización puede establecer en forma indirecta, es decir, aquellos que se producen utilizando otro actor como puente.

Esta última tipología de contacto resulta de importancia en la medida que los agentes hacen circular información o conocimientos de terceros por el ámbito de la red. 
REDES- Revista hispana para el análisis de redes sociales

Vol.14,\#3, Junio 2008

http: // revista-redes.rediris.es

El enfoque de centralidad de cercanía 7 , a diferencia de la medida grado de centralidad, no enfatiza la naturaleza del vínculo que une a los actores sino que hace hincapié en la distancia de un actor a otro, concentrándose en la distancia geodésica, es decir, la ruta más corta que un actor debe seguir para llegar a otro nodo.

Los resultados de la centralidad de cercanía se presentan a continuación.

\begin{tabular}{|lc|r|r|}
\hline & & inCloseness & outCloseness \\
\hline 7 & MBB & 86.486 & 94.118 \\
\hline 8 & UNS & 84.211 & 91.429 \\
\hline 19 & EZFBBCR & 82.051 & 71.111 \\
\hline 17 & CGPBB & 80.000 & 88.889 \\
\hline 11 & UTN & 80.000 & 82.051 \\
\hline 3 & UIBB & 74.419 & 74.419 \\
\hline 1 & CClyS & 69.565 & 82.051 \\
\hline
\end{tabular}

Tabla 8

El análisis de los datos muestra que los actores más cercanos al resto por grado de salida son la MBB, la UNS, el CGPBB, la UTN y la CCIyS.

En el caso de la cercanía por grados de entrada, los agentes principales son nuevamente la MBB y la UNS, apareciendo en tercer término el EZFBBCR, que alcanza una suma de distancias geodésicas de 82; luego se encuentran el CGPBB y la UTN con 80 respectivamente.

A continuación se muestran las estadísticas descriptivas de la red.

\begin{tabular}{|lc|r|r|}
\hline & & inCloseness & outCloseness \\
\hline 1 & Mean & 66.304 & 67.033 \\
\hline 2 & Std Dev & 8.618 & 11.102 \\
\hline 3 & Sum & 2.188 .021 & 2.212 .104 \\
\hline 4 & Variance & 74.278 & 123.245 \\
\hline 5 & SSQ & 147.525 .063 & 152.352 .094 \\
\hline 6 & MCSSQ & 2.451 .189 & 4.067 .093 \\
\hline 7 & Euc Norm & 384.090 & 390.323 \\
\hline 8 & Minimum & 55.172 & 43.836 \\
\hline 9 & Maximum & 86.486 & 94.118 \\
\hline
\end{tabular}

Network in-Centralization $=42.30 \%$

Network out-Centralization $=56.76 \%$

Tabla 9

\footnotetext{
${ }^{7}$ El enfoque de centralidad de cercanía se utiliza habitualmente en matrices simétricas, pero UCINET permite calcular la medida para matrices normales diferenciando entre cercanía por lazos de entrada y cercanía por lazos de salida.
} 
REDES- Revista hispana para el análisis de redes sociales

Vol.14,\#3, Junio 2008

http: //revista-redes.rediris.es

Del análisis de los datos surge que el valor promedio de cercanía por lazo de entrada es de 66 caminos geodésicos y el de salida resulta de 67, siendo los valores máximos de 86 y 94 respectivamente.

A su vez, los índices de centralidad muestran un substancial grado de concentración en la red, tanto de salida como de entrada lo cual implica la existencia de actores con posiciones centrales en el sistema analizado.

\subsection{Grado de intermediación}

La importancia que un actor tiene en una red puede deberse a su capacidad para controlar la comunicación entre las diversas organizaciones.

La medida de grado de intermediación intenta captar este fenómeno, considerando todos los caminos geodésicos posibles entre los pares de nodos existentes en la red.

La Tabla 10 muestra la información correspondiente a la capacidad de intermediación de los principales agentes.

\begin{tabular}{|ll|r|r|}
\hline & & Betweenness & nBetweenness \\
\hline 7 & MBB & 81.447 & 8.210 \\
\hline 8 & UNS & 68.214 & 6.876 \\
\hline 17 & CGPBB & 66.714 & 6.725 \\
\hline 11 & UTN & 44.735 & 4.510 \\
\hline 12 & FUNDATEC & 39.701 & 4.002 \\
\hline 19 & EZFBBCR & 29.302 & 2.954 \\
\hline 1 & CCIyS & 25.515 & 2.572 \\
\hline 15 & CERZOS & 23.176 & 2.336 \\
\hline
\end{tabular}

Tabla 10

De acuerdo a la información suministrada por el cuadro, el actor con mayor grado de intermediación es la MBB, que se encuentra en 81 caminos geodésicos; la siguen la UNS, el CGPBB y la UTN, respectivamente.

Estos cuatro agentes disponen de un cierto poder en la red.

A su vez, el grado de intermediación en términos porcentuales arroja valores de un $8.2 \%$ para el caso de la MBB, un $6.8 \%$ para la UNS y un $6.7 \%$ para el caso del CGPBB. 
REDES- Revista hispana para el análisis de redes sociales

Vol.14,\#3, Junio 2008

http://revista-redes.rediris.es

Esta situación muestra cierta capacidad de los actores para controlan la circulación de información, permitiendo que este grupo actúe como intermediario o facilitador.

Por otro lado, existe una importante variabilidad en la capacidad de negociación o mediación de los agentes considerados, la cual fluctúa entre 0 y $\quad 8 \%$ respectivamente.

La Tabla 11 muestra las estadísticas descriptivas sobre intermediación en la red considerada.

\begin{tabular}{|lc|r|r|}
\hline & Betweenness & nBetweenness \\
\hline 1 & Mean & 17.030 & 1.717 \\
\hline 2 & Std Dev & 20.763 & 2.093 \\
\hline 3 & Sum & 562.000 & 56.653 \\
\hline 4 & Variance & 431.095 & 4.381 \\
\hline 5 & SSQ & 23.797 .158 & 241.825 \\
\hline 6 & MCSSQ & 14.226 .127 & 144.565 \\
\hline 7 & Euc Norm & 154.263 & 15.551 \\
\hline 8 & Minimum & 0.111 & 0.011 \\
\hline 9 & Maximum & 81.447 & 8.210 \\
\hline
\end{tabular}

Network Centralization Index $=6.70 \%$

Tabla 11

La intermediación promedio por actor es de 17 caminos geódesicos, existiendo también una importante variabilidad (desvío estándar igual a 20; mínimo 0 y máximo 81).

De acuerdo a la información suministrada por el programa, la centralidad de la red es significativamente baja $(6.70 \%)$, pese a existir un importante desvío estándar.

\section{Proyectos conjuntos entre las organizaciones}

Una alternativa para evaluar las relaciones existentes en el entramado institucional de apoyo a la producción consiste en considerar la cantidad de proyectos económicos conjuntos entre las distintas organizaciones.

Según Flores (1989), el diseño de un proyecto conjunto entre dos o más entidades implica un estadío superior de comunicación, donde se afianzan conversaciones y compromisos y se establece un nivel de coordinación que obliga a la producción sistemática de información consensuada entre las partes.

De acuerdo al ILPES (1966) se entiende por proyecto económico a una unidad de actividades de cualquier naturaleza, que requiere para su realización del uso o consumo de recursos escasos sacrificando beneficios actuales y asegurados, con la 
REDES- Revista hispana para el análisis de redes sociales

Vol.14,\#3, Junio 2008

http: // revista-redes.rediris.es

esperanza de obtener, en un período de tiempo mayor, beneficios superiores a los que se obtienen con la asignación actual de dichos recursos.

La Ilustración 3 refleja los lazos establecidos por las entidades bahienses a partir de diversos proyectos económicos.

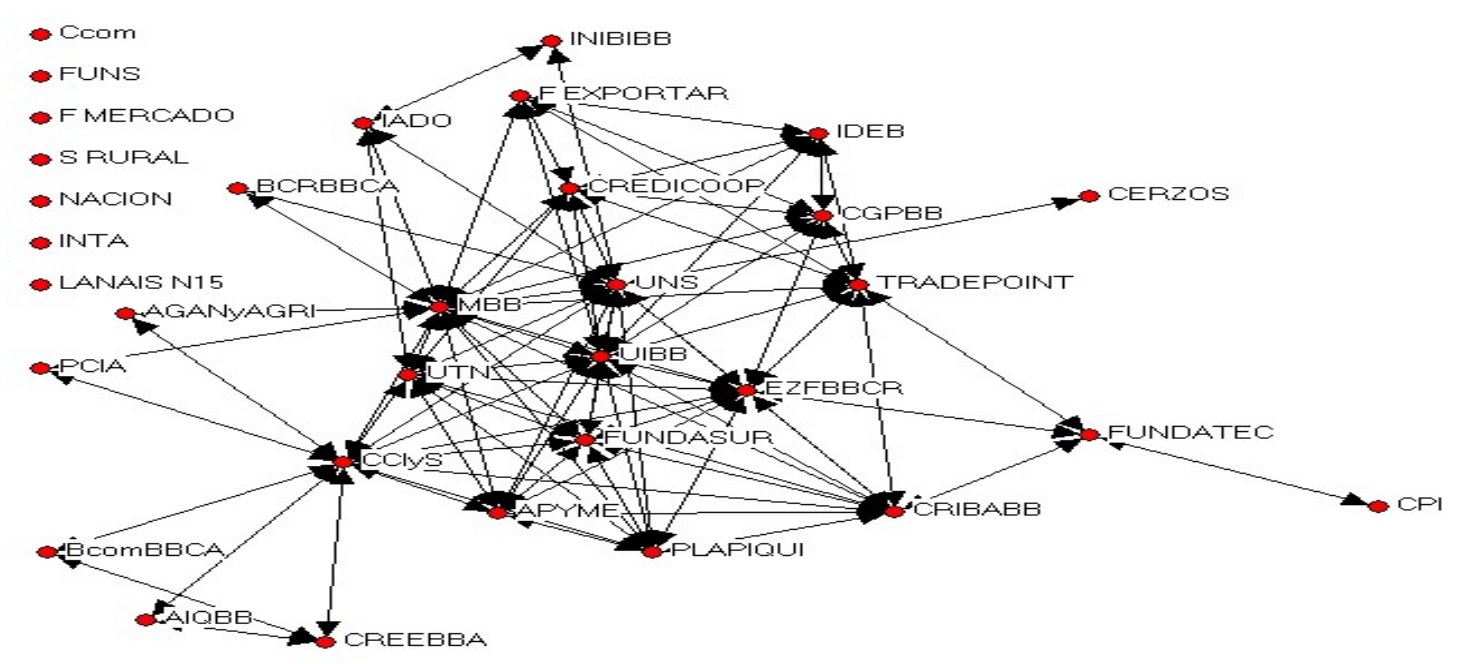

I lustración 3. Relaciones entre las entidades de Bahía a partir de proyectos económicos.

Este tipo concreto de redes se conoce como redes de afiliación o redes de implicancia mutua (Waserman y Faust, 1994), ya que el vínculo entre dos actores se forma cuando ambas organizaciones declaran estar realizando un proyecto en forma conjunta8.

En el caso particular de Bahía Blanca, las organizaciones de apoyo a la producción disponen al momento de las entrevistas de un total de 46 proyectos de colaboración o de carácter cooperativo.

Este número puede ser considerado bajo si se lo compara con estudios similares realizados para otras ciudades de Argentina, en los cuales se obtuvieron valores sensiblemente superiores con un número menor de entidades entrevistadas ${ }^{9}$.

\footnotetext{
${ }^{8}$ Los proyectos declarados fueron de diversa naturaleza. Algunos apuntaban a mejorar el entorno físico o "hardware" del desarrollo (Incubadora de Empresas, CIAPYME, Mantenimiento de la red vial rural, área metropolitana de la Bahía, Proyecto Remodelación del Centro); otros buscaban a la consolidación del "software", es decir facilitar la transferencia de información y know-how entre organizaciones (proyectos grupo de investigación (PGI) Universidad Nacional del Sur, Soporte tecnológico PIBB). También existían aquellos que promovían la optimización del "orgaware" u organización del territorio (Ente Polo Tecnológico, Centro Logístico de la ría de Bahía Blanca). Por último, existía un proyecto con cierto componente "finware" o de financiamiento (Programa Emprendedores Siglo XXI).

9 Ferraro y Costamagna (2002) en su trabajo sobre la ciudad de Mar del Plata identificaron un total de 142 proyectos conjuntos entre 27 organizaciones estudiadas.
} 
REDES- Revista hispana para el análisis de redes sociales

Vol.14,\#3, Junio 2008

http: // revista-redes.rediris.es

Del total de proyectos relevados en Bahía Blanca, sólo 12 (26\%) son realizados por más de dos organizaciones del entramado, lo cual puede significar ciertos condicionamientos por parte de los agentes para compartir recursos.

A su vez, un total de $25 \%$ involucran a organizaciones pertenecientes a distintos grupos (54\%) y 21 (46\%) corresponden a entidades consideradas dentro de la misma categoría.

Respecto a este punto, resulta importante destacar que 18 son realizados exclusivamente por entidades de ciencia y tecnología, lo cual muestra cierta tendencia a la retroalimentación en el seno de este grupo. Esta situación resulta particularmente evidente en el caso de las entidades más especializadas, que comparten proyectos casi en forma exclusiva con las universidades nacionales.

Por su parte, la organización que más proyectos declaró tener con otras instituciones fue la UNS con un total de 26, seguida de la MBB con 13, el Centro de Recursos Naturales Renovables de la Zona Semiárida10 (CERZOS) con 10 y la cClys con 8.

Los resultados observados en este sentido parecen ser consistentes con lo manifestado en la teoría de redes, en la que se sostiene que las entidades más complejas suelen tener mayor cantidad de actividades de colaboración que aquellas organizaciones que disponen de una estructura más simple (Sanz Menéndez et al, 1999).

Por último y como puede observarse en la figura 2, existe un grupo de 7 actores (Ccom, FUNS, F MERCADO, S RURAL, NACION, INTA, LANAIS № 15) que no tienen proyectos conjuntos con otras entidades del entramado.

\section{Liderazgos institucionales}

Utria (1981) plantea como elemento fundamental del desarrollo territorial el grado de organización existente en una comunidad.

Según el autor, una comunidad dinámica que experimenta un cambio activo a favor del desarrollo contiene en su seno una dosis de conflicto y de puja de intereses, pero en la búsqueda del progreso social y económico la población debe estar integrada para asegurar un grado razonable de acuerdo y de unidad de acción. 
REDES- Revista hispana para el análisis de redes sociales

Vol.14,\#3, Junio 2008

http: // revista-redes.rediris.es

Esta noción de búsqueda de consenso y cooperación remite necesariamente al concepto de governance el cual puede entenderse como "el campo de resolución de problemas (para)políticos (en el sentido de problemas de búsqueda colectiva de objetivos o realización de propósitos comunes) en, y a través de configuraciones específicas de instituciones, organizaciones y prácticas gubernamentales (jerárquicas) y extragubernamentales (no jerárquicas)" (J essop, 1999).

De acuerdo a esta visión, resulta de suma importancia el papel que juegan las organizaciones territoriales y sus líderes como catalizadores y guías de la ciudadanía, capaces de impulsar una estrategia que contenga y sintetice diferentes aspiraciones.

Esta perspectiva supone que cuanto más eficiente sea la organización del territorio y genuino el liderazgo ${ }^{11}$, más estará la comunidad local en condiciones de desempeñar un papel activo y eficiente en las tareas del desarrollo.

Para intentar evaluar la presencia o ausencia de liderazgos locales, D`Annunzio (2000), Costamagna (2000) y Ferraro y Costamagna (2002) desarrollaron una metodología que permite el estudio de cuatro puntos claves para el desarrollo económico local.

Esta consiste en instar a los referentes locales a nombrar de manera objetiva a aquellos agentes que consideran líderes en cuatro temas, existiendo la posibilidad de auto evaluación.

Los temas a considerar son los siguientes:

- Generación de iniciativas y propuestas.

- Capacidad para articular y generar consenso entre las distintas entidades.

- Capacidad de negociación con actores externos al ámbito local.

- Visión Estratégica de Futuro con respecto a temas vinculados al desarrollo económico del partido.

\footnotetext{
${ }^{10}$ Resulta interesante destacar que el CERZOS sólo declaro tener proyectos conjuntos con la Universidad Nacional del Sur a través de la Secretaría de Ciencia y Tecnología.

11 El liderazgo se concibe como la habilidad, en base a cualidades propias de la organización, para obtener la subordinación voluntaria de otras entidades en una amplia gama de asuntos.
} 
REDES- Revista hispana para el análisis de redes sociales

Vol.14,\#3, Junio 2008

http://revista-redes.rediris.es

Los resultados de la investigación para el caso Bahía Blanca se presentan a continuación.

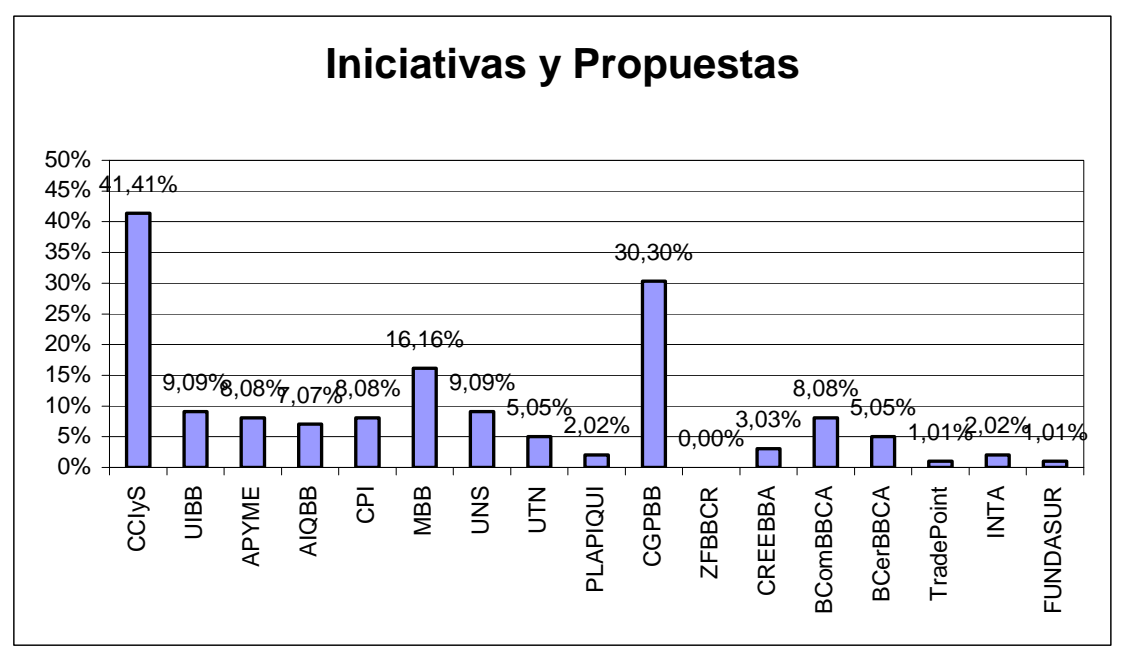

\section{I lustración 4}

De acuerdo al gráfico y como es de esperar en un sistema económico basado en la iniciativa privada, el mayor valor del indicador lo obtiene la CClyS, seguido en segundo lugar del CGPBB y en tercer lugar por la MBB.

El resto de las organizaciones presenta resultados que pueden significar una gran dispersión.

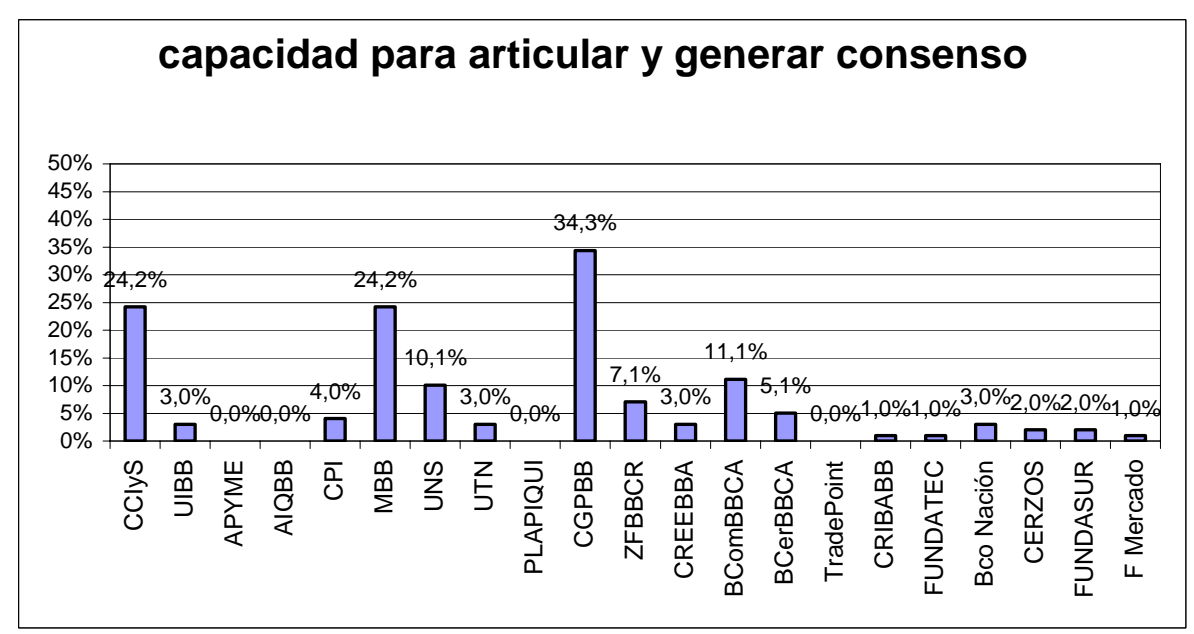

\section{I lustración 5}

En relación con la "capacidad para articular y generar consenso", se repite una situación similar a la anterior. 
REDES- Revista hispana para el análisis de redes sociales

Vol.14,\#3, Junio 2008

http: // revista-redes.rediris.es

Sin embargo, en este apartado el liderazgo es ejercido en primer lugar por el CGPBB, seguido en segundo término por la CClyS y la MBB.

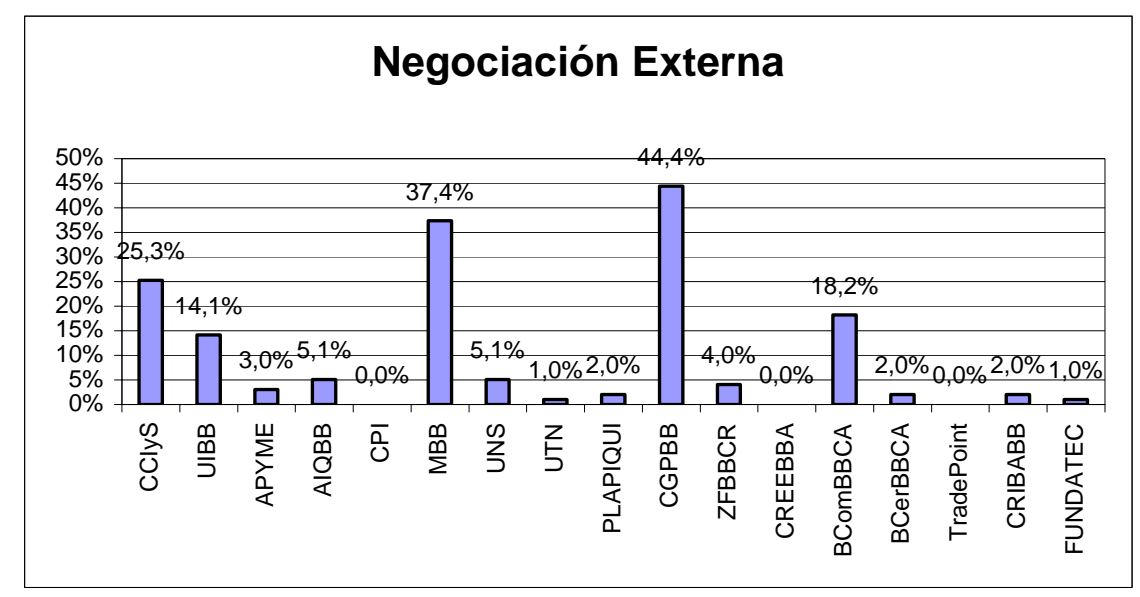

I lustración 6

Como en el caso anterior, los resultados sobre negociación externa vuelven a colocar a las mismas organizaciones obteniendo los valores más altos del indicador. En cuarto y quinto lugar, pero obteniendo valores significativamente más bajos aparecen la BcomBBCA y la UIBB.

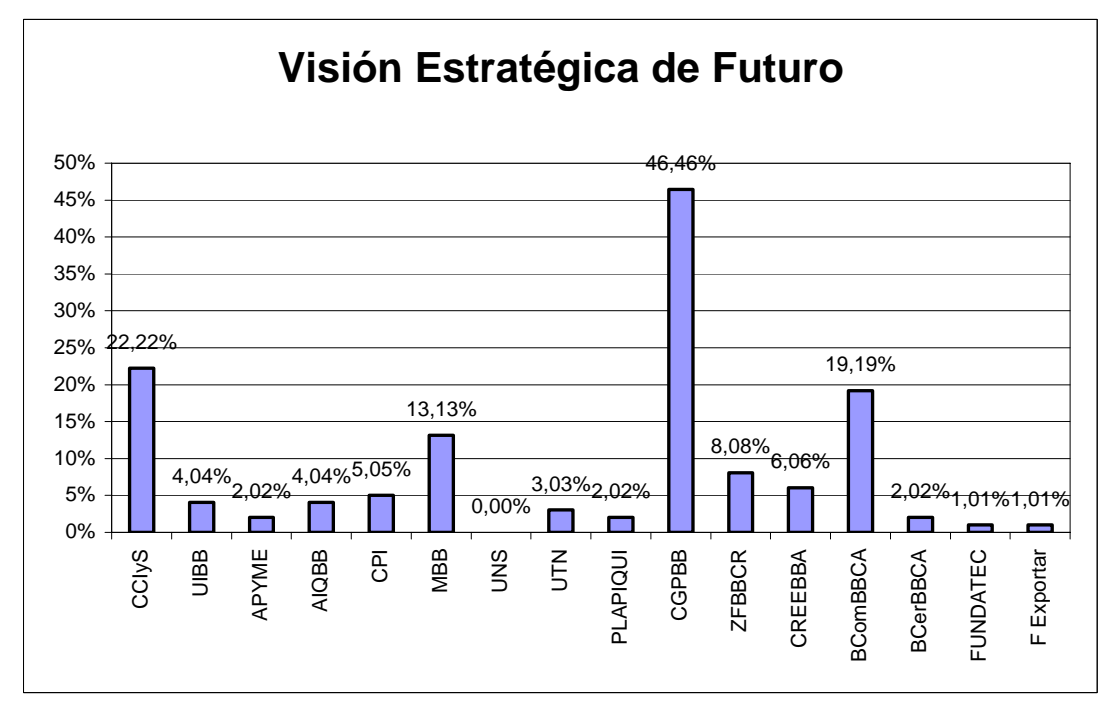

\section{I lustración 7}

Por último, en lo relacionado a la "Visión Estratégica de Futuro" existe un liderazgo muy marcado del CGPBB, seguido de la CClys y la BcomBBCA. El resto de las organizaciones no alcanza valores significativos del indicador. 
REDES- Revista hispana para el análisis de redes sociales

Vol.14,\#3, Junio 2008

http: // revista-redes.rediris.es

Además, resulta importante destacar que 4 organizaciones no emitieron opinión en este apartado por considerar que no existían en la ciudad instituciones con visión estratégica de futuro.

\section{Conclusiones}

Los nuevos enfoques sobre desarrollo territorial destacan la importancia del tejido institucional como determinante de los procesos de acumulación de capital y de cambio estructural de la economía local.

De acuerdo a estas nuevas visiones, el desarrollo económico toma lugar en aquellos territorios donde los actores públicos y privados priorizan acciones colectivas por sobre las individuales, promoviendo redes horizontales entre agentes que favorezcan la interrelación de activos y destrezas, facilitando la circulación de la información y reduciendo la incertidumbre y los costos de transacción.

En este sentido, la densidad institucional (Amin y Thrift, 1993) es entendida como una mayor capacidad territorial para el desarrollo. Esta noción supone una cultura de compromiso y colaboración, creencias que permitan llevar adelante un destino común.

En el caso particular de Bahía Blanca (Argentina), el entramado institucional de apoyo a la producción parece no relacionarse adecuadamente.

La densidad de vínculos entre las organizaciones puede catalogarse como media baja, ya que sólo están presentes un $48 \%$ de las comunicaciones posibles. Por su parte, también existe un importante nivel de "ruido" en las relaciones institucionales, ya que 19 organizaciones manifestaron enviar información a más entidades de las que efectivamente la recibían.

Por otro lado, los problemas relativos a la comunicación parecen no deberse a limitaciones en la estructura interna de cada organización.

En este sentido, un $64 \%$ de los entrevistados manifestó disponer de personal adecuado para desarrollar sus actividades y un $97 \%$ sostuvo disponer de personal de calificación alta.

También resultó alto el número de entidades que manifestaron brindar capacitaciones al personal, aunque sólo tres disponen de un programa anual de calificación de recursos humanos (PCIA, NACION y CREDICOOP). 
REDES- Revista hispana para el análisis de redes sociales

Vol.14,\#3, Junio 2008

http://revista-redes.rediris.es

Además los entrevistados también consideraron como adecuado el equipamiento disponible y los recursos técnicos asociados a la comunicación.

En cuanto a la información que surge de las diferentes medidas de análisis de la red, se destaca la importancia de tres actores (MBB, CGPBB y UNS) por sobre el resto.

En este sentido, sus grados de salida, entrada, intermediación y cercanía son superiores a la media.

En un segundo escalón podemos destacar el caso de la UTN, EZFBBCR, la UIBB y la cClys.

Este grupo de 7 actores parece concentrar el mayor número de relaciones en la red y es debido a esto que se registra una importante centralidad de salida (46\%) y de entrada (37\%) en el entramado.

En cuanto a la cantidad de proyectos conjuntos entre las entidades estudiadas, podemos afirmar que el número es bajo si se lo compara con otras experiencias en las que se ha utilizado una metodología de estudio similar, lo que evidencia una falta de sinergia en el sistema.

Las organizaciones que declararon más proyectos conjuntos son la UNS, la MBB, el CERZOS y la CClys.

Del total de proyectos relevados, sólo 12 (26\%) son realizados por más de dos asociaciones del sistema considerado.

Por su parte, un total de 25 (54\%) involucra a organizaciones clasificadas como pertenecientes a distintos grupos y 21 (46\%) corresponden a organizaciones consideradas dentro de la misma categoría.

Dentro de aquellos conformados por entidades del mismo tipo, 18 son realizados por entes de ciencia y la tecnología.

Este punto evidencia cierta tendencia a la retroalimentación entre las organizaciones del campo científico, principalmente por parte de las entidades más especializadas (CERZOS, INIBIBB, IADO) que se vinculan mayoritariamente con las universidades nacionales, interactuando en menor medida con el resto de los actores. 
REDES- Revista hispana para el análisis de redes sociales

Vol.14,\#3, Junio 2008

http: // revista-redes.rediris.es

Por otro lado y de acuerdo a la información recopilada, la UNS y la MBB están haciendo un buen uso de los recursos existentes en la red, ya que la temática de los proyectos declarados es amplia y diversa.

Pese a esta situación, ambas entidades registran valores bajos en dos indicadores de liderazgo: "Iniciativas y Propuestas" y "Visión Estratégica de Futuro".

De acuerdo a los entrevistados, los proyectos que son liderados tanto por la UNS como por MBB carecen de un marco estratégico explícito que los contenga.

Esta limitación constituye una debilidad para ambas organizaciones, ya que ven afectada su capacidad de posibles conductoras o dinamizadoras a futuro de un proceso de desarrollo para la ciudad.

A su vez, en el caso particular de la UNS, también resulta llamativo el bajo valor registrado en el indicador "articulación y generación de consenso", ya que la entidad registra una importante capacidad de intermediación dentro de la trama considerada.

Esta situación da cuenta de una subutilización de las relaciones generadas por la casa de estudio, que podrían tener un papel más relevante en el diseño de mecanismos de governance para territorio, dada la amplitud de sus contactos.

Por último y respecto a esta serie de indicadores, también resulta interesante analizar el caso del CGPBB.

Esta organización pese a no participar de muchos proyectos conjuntos obtiene el valor más alto en el indicador "Visión Estratégica de Futuro" y el segundo lugar en el índice "Iniciativas y propuestas".

Estos resultados parecen evidenciar cierta capacidad de la entidad para potenciar su imagen institucional a través de su red contactos.

\section{Bibliografía}

Amin, A., Thrift, N. (1993). "Globalization, institutional thickness and local prospects" Revue d`Economie Regionale et Urbaine;№3 pág. 405-430.

Aydalot, P. (1986). Milieux innovateurs en Europe. Paris, GREMI.

Boisier, S. (1997), El vuelo de una cometa. Una metáfora para una teoría del desarrollo territorial. Serie Ensayos ILPES 97/37. ILPES, Santiago de Chile. 
REDES- Revista hispana para el análisis de redes sociales

Vol.14,\#3, Junio 2008

http: // revista-redes.rediris.es

Borgatti, S.P., Everett, M. G., Freeman, L. C. (2002). Ucinet for Windows: Software for Social Network Analysis, Harvard, MA: Analytic Technologies.

Borgatti, S. P. (2002). Netdraw: Graph Visualization Software. Harvard: Analytic Technologies.

Choucri, Nazli (2001). "Red de conocimientos para un salto tecnológico" en Revista Cooperación Sur, PNUD-CTPD, № 2.

Colletis, G., Pecqueur, B. (1995). «Role des politiques technologiques dans la creation de ressources spécifiques et davantages dynamiques de localisation » en Rallet, A., Torre, A. (dirts) Économie industrielle et économie spatiale. París, Económica.

Costamagna, Pablo (2000). La articulación y la interacción entre instituciones: la iniciativa de desarrollo económico local de Rafaela, Argentina. Santiago de Chile, Naciones Unidas.

D’Annunzio, Claudia (2000). Iniciativa de Desarrollo Económico Local. La articulación y las interacciones entre instituciones: el caso Tandil, Argentina. Santiago de Chile, Naciones Unidas.

de Mattos, Carlos A., Fuentes Arce, Luis, Sierralta Jorquera, Carlos (2004). Santiago, ¿ciudad de clase mundial? Factores en el posicionamiento de internacional de Santiago de Chile. Santiago de Chile, EURE libros.

Dominguez Ares, Elvira (1999). Las organizaciones como instrumento de desarrollo local. Trabajo Profesional Fin de Carrera (inédito). Escuela Técnica Superior de Ingenieros Agrónomos y de Montes Universidad de Córdoba España.

Durston, J. (2002), El capital social campesino en la gestión del desarrollo rural: díadas, equipos, puentes y escaleras. Comisión Económica para América Latina y el Caribe (CEPAL), Santiago de Chile.

Erbiti, Cecilia (2004). Los condicionantes del desarrollo endógeno en las ciudades de la macroregión pampeana: el caso Tandil, Argentina. Tesis Doctoral (inédito). Facultad de Filosofía y Letras Universidad Autónoma de Madrid.

Escarpit, Ronald (1976). Teoría general de la información y la comunicación. Barcelona, Icaria.

Ferraro, Carlo, Costamagna, Pablo (2002). Competitividad territorial e instituciones de apoyo a la producción en Mar del Plata. Santiago de Chile, Naciones Unidas.

Flores, F. (1989), Inventando la empresa del siglo XXI. Santiago de Chile, Hachette.

Harrigan, Kathy (1996). J oint Venture. Buenos Aires, Tesis-Norma.

Ilpes (1966), Discusiones sobre Planificación. Santiago de Chile, Editorial Siglo XXI.

Jessop, Bob (2005). "El ascenso del buen gobierno y los riesgos del fracaso: el caso del desarrollo económico" En: Coloquio Les enjeux des debats sur la governance. En línea: htpp://www.UNESCO.org/155j/rics115/jessopspa.html.

Maillat,D. (1995). «Les millieux innovateurs » en Sciencies Humaines, no 8. 
REDES- Revista hispana para el análisis de redes sociales

Vol.14,\#3, Junio 2008

http: // revista-redes.rediris.es

Maisonneuve, Jean (1968). La dinámica de los grupos. París, PUF.

Morgan, G. (1986). Imágenes de las organizaciones. Distrito Federal, Alfaomega.

Shannon, C. E, Weaver, W. (1949). Teoría matemática de la comunicación. Madrid, Forja.

Sanz Menéndez, Luis, FERNANDEZ CARRO, José R., GARCíA, Clara E., (1999). "Centralidad y cohesión en las redes de colaboración empresarial en la I+D subsidiada" en Revista Papeles de Economía Española, №81.

Utria, Rubén (1981). “Algunos aspectos sociales del desarrollo regional en América Latina" en Kuklinski, A. (comp.) Aspectos sociales de la Política y de la Planeación Regional, Distrito Federal México, Fondo de Cultura Económica.

Vázquez Barquero, A. (2001)." Desarrollo Endógeno y Globalización" en Vázquez Barquero, A., Madoery, O. (comp.) Transformaciones Globales, instituciones y políticas de desarrollo local. Rosario, HomoSapiens.

Wasserman, Stanley, Faust, Catherine (1994). Social Network Análisis. Methods and Applications. Cambridge, Cambridge University Press. 
REDES- Revista hispana para el análisis de redes sociales

Vol.14,\#3, Junio 2008

http: //revista-redes.rediris.es

\section{Anexo I}

\begin{tabular}{|c|c|}
\hline \multicolumn{2}{|l|}{ Mapa I nstitucional de Bahía Blanca } \\
\hline Entidades gremiales empresarias & $\begin{array}{l}\text { Corporación de Comercio, la Industria y los Servicios } \\
\text { de Bahía Blanca (CCIyS). } \\
\text { Cámara de Comercio de Bahía Blanca (Ccom). } \\
\text { Unión Industrial de Bahía Blanca (UIBB). } \\
\text { Asamblea de Pequeños y Medianos Empresarios } \\
\text { Bahía Blanca (APYME). } \\
\text { Asociación de Industrias Químicas de Bahía Blanca } \\
\text { (AlQBB). } \\
\text { Asociación de Ganaderos y Agricultores del Partido de } \\
\text { Bahía Blanca (AGANyGRI). }\end{array}$ \\
\hline Instituciones Educativas y Científico Tecnológicas & $\begin{array}{l}\text { Universidad Nacional del Sur (UNS). } \\
\text { Fundación de la Universidad Nac. Del Sur (FUNS). } \\
\text { Universidad Tecnológica Nacional Facultad Regional } \\
\text { Bahía Blanca (UTN). } \\
\text { Fundación de la Universidad Tecnológica Nacional } \\
\text { Facultad Regional Bahía Blanca (FUNDATEC). } \\
\text { Centro Regional de Investigaciones Básicas y } \\
\text { Aplicadas Bahía Blanca (CRIBABB). } \\
\text { Planta Piloto de Química e Ingeniería Química } \\
\text { (PLAPI QUI). } \\
\text { Fundación del Sur para del Desarrollo Tecnológico } \\
\text { (FUNDASUR). } \\
\text { Insituto de Investigaciones Bioquímicas de Bahía } \\
\text { Blanca (INIBIBB). } \\
\text { Centro de Recursos Naturales Renovables de la Zona } \\
\text { Semiárida (CERZOS). } \\
\text { Instituto Argentino de Oceanografía (IADO). } \\
\text { Laboratorio de Análisis de Nitrógeno 15 (LANAIS N } \\
\text { 15). } \\
\text { Instituto Nacional de Tecnología Agropecuaria oficina } \\
\text { Bahía Blanca (INTA). }\end{array}$ \\
\hline Gobierno local y Entes públicos no gubernamentales & $\begin{array}{l}\text { Municipalidad de Bahía Blanca (MBB). } \\
\text { Consorcio de Gestión del Puerto de Bahía Blanca } \\
\text { (CGPBB). } \\
\text { Ente Zona Franca Bahía Blanca Coronel Rosales } \\
\text { (EZFBBCR). }\end{array}$ \\
\hline Banca de Fomento Pública y Cooperativa & $\begin{array}{l}\text { Banco de la Nación Argentina (NACION). } \\
\text { Banco de la Provincia de Buenos Aires (PCIA). } \\
\text { Banco Credicoop Cooperativo Limitado (CREDICOOP). }\end{array}$ \\
\hline Entidades de Comercialización & $\begin{array}{l}\text { Bolsa de Cereales Productos y Oleaginosos de Bahía } \\
\text { Blanca (BCRBBCA). } \\
\text { Bolsa de Comercio de Bahía Blanca (BcomBBCA). } \\
\text { Sociedad Rural de Bahía Blanca (S RURAL) }\end{array}$ \\
\hline Otros Actores & $\begin{array}{l}\text { Fundación ExportAr of. Bahía Blanca (EXPORTAR). } \\
\text { Fundación Mercado (F MERCADO). } \\
\text { Centro Regional de Estudios Económicos de Bahía } \\
\text { Blanca (CREEBBA). } \\
\text { Trade Point Zona Franca Bahía Blanca Coronel } \\
\text { Rosales (TRADEPOINT). } \\
\text { Instituto de Desarrollo Empresario Bonaerense } \\
\text { (IDEB). } \\
\text { Consorcio de Gestión del Parque Industrial de Bahía } \\
\text { Blanca (CPI). }\end{array}$ \\
\hline
\end{tabular}


REDES- Revista hispana para el análisis de redes sociales

Vol.14,\#3, Junio 2008

http: // revista-redes.rediris.es

\section{Anexo II}

\begin{tabular}{|c|c|c|}
\hline $\mathbf{N}^{\circ}$ & Nombre del Proyecto & Organizaciones que intervienen \\
\hline 1 & Ente Polo Tecnológico & $\begin{array}{l}\text { APYME CCIyS CRIBABB EZFBBCR PLAPIQUI } \\
\text { FUNDASUR UIBB UNS UTN MBB y otro }\end{array}$ \\
\hline 2 & Biorremediación del Arroyo El divisorio (PGI) & MBB UNS IADO y otros \\
\hline 3 & $\begin{array}{l}\text { Detección de Virus en Crustáceos y Tóxinas en } \\
\text { Moluscos (PGI) }\end{array}$ & UNS INIBIBB IADO y otro \\
\hline 4 & $\begin{array}{l}\text { Factores Bacteriológicos, Químicos y Nutricionales } \\
\text { que influencian la calidad de la carne de conejo a } \\
\text { nivel regional (PGI) }\end{array}$ & UNS MBB BCRBBCA y otros \\
\hline 5 & $\begin{array}{l}\text { Determinación de los efectos del genotipo y el } \\
\text { ambiente sobre la calidad del trigo candeal (PGI) }\end{array}$ & UNS BCRBBCA \\
\hline 6 & Ferrocarril Trasandino del Sur-Corredor Bioceánico & BCOMBBCA CREEBBA y otros \\
\hline 7 & CIAPYME & APYME MBB \\
\hline 8 & Incubadora de Empresas & EZFBBCR TRADE POINT CRIBABB FUNDATEC \\
\hline 9 & Mesa de Comercio Exterior & $\begin{array}{l}\text { F EXPORTAR TRADEPOINT } \\
\text { MBB IDEB UIBB CREDICOOP CGPBB y otros }\end{array}$ \\
\hline 10 & Corredor Turístico Bahía Blanca-Ing. White & MBB UNS \\
\hline 11 & Fomento Exportación de PYMES & MBB CClyS \\
\hline 12 & Consorcio Ovino & MBB CClyS AGANyAGRI \\
\hline 13 & Mantenimiento de la red vial rural & AGANyAGRI MBB \\
\hline 14 & FISA-Ronda de Negocios & MBB CClyS \\
\hline 15 & Remodelacion del Centro & CClyS BCOMBBCA \\
\hline 16 & Fuerza PyMe/Agro & PCIA MBB \\
\hline 17 & Convenio Bco Pcia/CClyS & PClA CClyS \\
\hline 18 & Avión Ultraliviano & CPI FUNDATEC y otro \\
\hline 19 & Programa Emprendedores Siglo XXI & CREDICOOP UNS UTN \\
\hline 20 & Programa Integral de Gestión de PYMES & CREDICOOP UTN \\
\hline 21 & Centro Logístico de la ría de Bahía Blanca & CGPBB EZFBBCR \\
\hline 22 & Encuestas de coyuntura & CCIyS CREEBBA \\
\hline 23 & Monitoreo Polo Petroquímico & AIQBB CREEBBA \\
\hline 24 & Soporte Tecnológico PIBB & FUNDATEC CPI \\
\hline 25 & Desarrollo de instrumental & UTN IADO \\
\hline 26 & $\begin{array}{l}\text { Monitoreo contaminación estuario de ría de Bahía } \\
\text { Blanca }\end{array}$ & UNS MBB IADO \\
\hline 27 & Proyecto Área Metropolitana de la Bahía (Ferro Ría) & CGPBB MBB y otros \\
\hline 28 & $\begin{array}{l}\text { Estudio de Catalizadores y Absorventes de interés } \\
\text { tecnológico (PGI) }\end{array}$ & PLAPIQUI UNS \\
\hline 29 & $\begin{array}{l}\text { Estudios de optimización avanzada en sistemas de } \\
\text { Ing. de procesos (PGI) }\end{array}$ & PLAPIQUI UNS \\
\hline 30 & $\begin{array}{l}\text { Investigación y transferencia de tecnologia en el } \\
\text { procesamiento de productos (PGI) }\end{array}$ & PLAPIQUI UNS \\
\hline 31 & Polímeros sintéticos de interés tecnológico (PGI) & PLAPIQUI UNS \\
\hline 32 & Termodinámica de productos naturales (PGI) & PLAPIQUI UNS \\
\hline 33 & $\begin{array}{l}\text { Estudio geográfico integral del Corredor Bioceánico } \\
\text { B.Bca.-Pto. Montt (PGI) }\end{array}$ & UNS MBB \\
\hline 34 & $\begin{array}{l}\text { Factores de cambio en la estructura urbana y la } \\
\text { dinámica económica bahiense (PGI) }\end{array}$ & UNS MBB IADO \\
\hline 35 & Territorio Innovación y Gobernabilidad (PGI) & UNS UTN \\
\hline 36 & $\begin{array}{l}\text { Pabellón Predio Corporación de Comercio Industria y } \\
\text { Servicios }\end{array}$ & AIQBB CClyS \\
\hline
\end{tabular}


REDES- Revista hispana para el análisis de redes sociales

Vol.14,\#3, Junio 2008

http: // revista-redes.rediris.es

\begin{tabular}{|c|c|c|}
\hline 37 & Degradación Antrópica de Suelos & UNS CERZOS \\
\hline 38 & Evaluación de dietas para bovinos en crecimiento & UNS CERZOS \\
\hline 39 & Amoniación de materiales de alto contenido en fibra & UNS CERZOS \\
\hline 40 & La soja ante deficiencias hídricas & UNS CERZOS \\
\hline 41 & $\begin{array}{l}\text { Reemplazo de pastos blandos por pastos duros y } \\
\text { mejoramiento forrajero }\end{array}$ & UNS CERZOS \\
\hline 42 & $\begin{array}{l}\text { Mapeo de genes involucrados en calidad de trigo } \\
\text { candeal }\end{array}$ & UNS CERZOS \\
\hline 43 & $\begin{array}{l}\text { Impacto de la utilización de pesticidas sobre } \\
\text { comunidades microbianas del suelo y su impacto en } \\
\text { la biorremediación }\end{array}$ & UNS CERZOS \\
\hline 44 & Fertilización Nitrogenada en cebada cervecera & UNS CERZOS \\
\hline 45 & $\begin{array}{l}\text { Evaluación de poblaciones silvestres de Helianthus } \\
\text { spp. En Argentina y su interacción con el trigo } \\
\text { cultivado }\end{array}$ & UNS CERZOS \\
\hline 46 & $\begin{array}{lrlll}\text { Bioecología y manejo de malezas en } \\
\text { agroecosistemas }\end{array}$ & UNS CERZOS \\
\hline
\end{tabular}

